\title{
Visual detection threshold differences between psychiatric patients and normal controls
}

\author{
SALVATORE MANNUZZA \\ Department of Psychophysiology, New York State Psychiatric Institute, New York, New York 10032 \\ BONNIE J. SPRING \\ Harvard University, Cambridge, Massachusetts 02138
}

\author{
MICHAEL D. GOTTLIEB and MITCHELL L. KIETZMAN \\ Department of Psychophysiology, New York State Psychiatric Institute, New York, New York 10032
}

\begin{abstract}
Previous investigations of the visual sensitivity of psychiatric patients have generally failed to control for confounding due to nonsensory factors. In the present research, visual detection thresholds of acute hospitalized psychiatric patients and nonpatients were obtained using an adaptive, criterion-free, three-interval, temporal, forced-choice double-staircase procedure. In Experiment 1, 23 schizophrenic patients and 13 nonpatient controls were tested; in Experiment 2, 17 schizophrenic patients, 15 patients with major depressive disorder, 15 siblings of schizophrenic probands, and 18 nonpatient controls were tested. Results of both experiments indicated that, on the average, patients required about twice as much luminous energy for absolute threshold detection, with about $50 \%$ overlap between patient and control distributions $(\mathrm{p}<.01$ in both studies). The present research suggests that there are differences in visual sensitivity between psychiatric patients and normal controls that cannot be attributed to response-bias factors. Implications of the present findings and directions for future research are discussed.
\end{abstract}

Research on the visual sensitivity of psychiatric subjects followed a World War II observation that the incidence of "night blindness" among neurotics was higher than among normal service personnel. Since that time, several investigators have shown that during the course of dark adaptation, psychiatric patients have elevated visual thresholds; that is, presumably, they are less sensitive (see Granger, 1957). Rubin and Stein (1960) reported that psychotics displayed significantly higher thresholds than normal controls and that the patients showed no change in visual sensitivity over 5 testing days. Beck (cited in Gerard, 1964) investigated the effects of oxygen inhalation on the visual sensitivity of schizophrenic and nonschizophrenic hospitalized mental patients. He found that oxygen lowered the thresholds of more than $80 \%$ of the 86 schizophrenic patients and less than $25 \%$ of the 34 nonschizophrenic patients tested.

Recent reviews of the sensory and perceptual literature in psychophathology suggest that findings of

S. Mannuzza and M. L. Kietzman are also at Queens College of the City University of New York. M. D. Gottlieb is now at Mount Sinai School of Medicine, Department of Neurology, New York City. The authors would like to thank S. Goldberg and L. Burton for their assistance in collecting and analyzing the data and S. Sutton for his helpful comments on an earlier draft of this paper. Requests for reprints should be sent to Salvatore Mannuzza, Department of Psychophysiology, New York State Psychiatric Institute, 722 W. 168th Street, New York, New York 10032. patient-nonpatient differences are equivocal because of imprecision in methodological design (Jenness, Kietzman, \& Zubin, 1975; Zubin, Salzinger, Fleiss, Gurland, Spitzer, Endicott, \& Sutton, 1975). A major concern is determining the extent to which patient-nonpatient differences can be attributed to sensory factors (i.e., that there are "genuine" sensory differences between patients and nonpatients). Sutton (1973) has indicated that perhaps some of the sensory, perceptual, conceptual, and psychomotor anomalies that have been reported in psychiatric patients are attributable to the patient's decreased motivation, cooperation, or attention during the testing session.

Contemporary psychophysics has provided researchers with procedures for measuring and controlling nonsensory factors. For example, signal detection theory (see Green \& Swets, 1966) has shown that nonsensory factors such as the subject's willingness to report seeing a light (i.e., the subject's response criterion or bias) play an important role in the determination of sensory thresholds (Clark, 1966). Thus, the interpretation of the findings of previous investigators who failed to employ signal detection methodology can be questioned (Frith, 1973). Clark, Brown, and Rutschmann (1967) demonstrated this point most effectively with respect to differences in the critical flicker frequency threshold.

In audition, Bruder, Spring, Yozawitz, and Sutton (in press) and Bruder, Sutton, Babkoff, Gurland, Yozawitz, and Fleiss (1975), using a forced-choice 
signal detection procedure, have shown that affective patients, but not schizophrenic patients, have significantly higher detection thresholds than do controls. Using the same procedure, Babkoff, Sutton, and Zubin (in press) measured auditory thresholds at three stimulus durations. Results indicated that the slopes of the functions relating sensitivity to stimulus duration differed for affective and nonaffective psychotics, both groups showing less auditory sensitivity than controls. Other auditory detection experiments using signal detection methodology also have reported that psychiatric patients are less sensitive than normal control subjects (Emmerich \& Levine, 1970; Malone \& Hemsley, 1977). These findings reopen the possibility that psychiatric patients display genuine sensory deficits, at least in audition, and they prompt us to reexamine with criterion-free methods whether patients are also less sensitive visually.

The present research represents an attempt to answer the question, are there "genuine" differences in visual sensitivity between psychiatric patients and nonpatients? In two independent experiments, visual thresholds of patients and nonpatients were obtained using an adaptive, forced-choice double-staircase procedure. The forced-choice procedure eliminates the possibility of confounding caused by differences in response criteria across subjects.

\section{EXPERIMENT 1}

\section{Method}

Subjects. The subjects were 23 psychiatric patients at Kingsboro Psychiatric Center with hospital diagnoses of schizophrenia and 13 nonpatient controls recruited from local colleges and from the New York State Employment Service. All subjects were males between the ages of 18 and 45 years, with no evidence of mental retardation, brain damage, or alcohol or drug addictions. The mean ages of the patients and nonpatients were 27.5 and 22.8 years, respectively. All patients were receiving some type of antischizophrenic medication.

Apparatus. The stimulus, a white-appearing circular target, subtended a visual angle of $21.8 \mathrm{~min}$ and was foveally fixated in binocular view. The light source was a glow-modulator tube (Sylvania R1131C), operating at a current of $23 \mathrm{~mA}$ and irradiated by an argon ultraviolet lamp (General Electric AR4). Light pulses were produced with rise and decay times of about 20 and 2 microsec, respectively. The glow-modulator's output was measured with a Pritchard Photometer (Photo Research Corporation) that was checked for accuracy using a 100-fL standard of luminance (Gamma Scientific 220-1).

Kodak Wratten neutral density filters and Tiffen metallic filters were used to manipulate stimulus luminance. A transistorized nine-channel timer (Logical Instruments) with an indeterminacy of 1 part in 10,000 controlled the duration of the light pulse $(2 \mathrm{msec})$ and other events within each trial.

Procedure. The block-up and down two-interval forcedchoice (BUDTIF) procedure (Campbell, 1963) was adapted to estimate the luminous intensity needed for $67 \%$ correct responses (50\% when adjusted for chance), in a three-interval temporal forced-choice task. ${ }^{1}$ Subjects were seated in a light-tight booth and were dark adapted for $5 \mathrm{~min}$. Each trial consisted of the following sequence of events: A click marked the beginning of a trial. After $2 \mathrm{sec}$, three tones separated by $.5 \mathrm{sec}$ were sounded. These tones, each $.5 \mathrm{sec}$ in duration, marked the three observation intervals. The target stimulus was presented $.1 \mathrm{sec}$ after the onset of one of the three tones. Following the termination of the last tone, the subject indicated his choice of intervals by pressing one of three buttons. A "beep" was sounded when the subject was correct.

Testing sessions ranged from about 45 to $60 \mathrm{~min}$. Rest periods of $1-2 \mathrm{~min}$ were given after every 10 blocks or at the subject's request. The intertrial interval was approximately $5 \mathrm{sec}$.

\section{Results}

The mean thresholds and standard deviations for patients and nonpatients are shown in Table 1. As a group, the patients required twice as much luminous energy as the nonpatients to detect the signal $50 \%$ of the time.

Table 1 also shows that there was a threefold difference in within-group variability between patients and nonpatients. An $\mathrm{F}$ test for homogeneity of variances (Edwards, 1972) indicated that patients were significantly more variable than nonpatients $[\mathrm{F}(22,12)=10.32$, $\mathrm{p}<.02$ ]. Since the homogeneity of variance assumption of parametric tests was violated, a nonparametric analysis was performed. A Mann-Whitney $U$ test indicated that the patients demonstrated significantly higher thresh. olds than the nonpatients $(\mathrm{z}=3.18, \mathrm{p}<.01$, two-tailed $)$. Inspection of the distributions of visual thresholds for patients and nonpatients indicated that 9 of the 23 patients (about 40\%) had higher thresholds than any nonpatient.

An index of within-subjects variability is given by the semi-interquartile range (SIQR) of the signal levels revisited in the "up" and "down" staircases. A MannWhitney U test indicated that the SIQRs of the patients' staircases were not significantly different from those of the nonpatients. By this criterion, patients and nonpatients did not differ in within-subjects variability.

\section{Discussion}

Consistent with previous investigations, the present experiment found a difference in visual thresholds between schizophrenic patients and normal controls. Whereas higher patient thresholds obtained in previous studies could have resulted from criterion differences, criterion was eliminated in the present experiment by means of a forced-choice procedure. The shapes of the "up-down" staircases for patients and nonpatients were highly similar, differing only in the signal level needed for $67 \%$ correct performance. For all subjects, ascending and descending staircases converged, thereafter remaining around the signal level reached at the point of convergence. This indicated that all subjects were performing the task properly (Cornsweet, 1962). Further, the finding that within-subjects variability (as measured by the SIQR) did not differ between patients and nonpatients suggests that the difference in visual thresholds did not result from less participation or engagement on the part of the patients.

Experiment 2 represents an extension of Experiment 1 in

Table 1

Mean Visual Thresholds (in Millilamberts/Milliseconds) and Standard Deviations of Patients and Nonpatients in Experiment 1

\begin{tabular}{llcl}
\hline \multicolumn{1}{c}{ Group } & N & Mean & SD \\
\hline Patients & 23 & .41 & .25 \\
Nonpatients & 13 & .20 & .08 \\
\hline
\end{tabular}


that specific diagnostic criteria, rather than hospital diagnoses, were employed and visual thresholds were obtained for patients with a major depressive disorder, as well as for siblings of schizophrenic probands.

\section{EXPERIMENT 2}

\section{Method}

Subjects. Sixty-five subjects were tested: 17 schizophrenic patients, 15 patients with major depressive disorder, 15 siblings of schizophrenic probands, and 18 nonpatient control subjects.

All subjects were males between the ages of 18 and 36 years. Attempts were made to match schizophrenic patients, depressed patients, and controls on age, ethnicity, and educational level. The mean ages of schizophrenic patients, depressed patients, siblings, and controls were 27.1, 25.7, 26.8, and 25.9 years, respectively. There was no significant difference between groups in age. The mean educational levels (highest grade completed in school) of these groups were $11.2,10.9,12.7$, and 11.9. The siblings of schizophrenic patients exhibited a significantly higher educational level than the schizophrenic patients $[\mathrm{t}(30)=$ $2.84, \mathrm{p}<.01]$ and the depressed patients $[\mathrm{t}(28)=2.54, \mathrm{p}<.02]$.

All patients were tested within 2 weeks of admission to Kingsboro Psychiatric Center; all were receiving some type of antischizophrenic medication. Schizophrenic and depressed patients did not differ significantly in the medication dosages they received as measured by mean daily equivalents of chlorpromazine (see Davis, 1976) expressed in milligrams per kilogram of body weight.

Patients were classified on the basis of a chart review and the information obtained during a screening interview, which required about $20 \mathrm{~min}$ to administer and was usually conducted jointly by two members of the project team. Only patients fulfilling the research diagnostic criteria (Spitzer, Endicott, \& Robins, 1978) for schizophrenia or major depressive disorder and having no evidence of brain damage, mental retardation, drug addiction, or alcohol abuse were accepted for testing.

Nonpatient control subjects were recruited from the New York State Employment Service and were screened to exclude cases with a familial history of psychiatric hospitalization. Information about hospitalization was confirmed by the New York State Department of Mental Hygiene. This service was also used to confirm that siblings of patients had never been hospitalized for a psychiatric disorder.

The apparatus and procedure used were the same as those of Experiment 1.

\section{Results}

The mean thresholds and standard deviations for schizophrenics, depressives, siblings, and controls are shown in Table 2. Both patient groups had higher thresholds and were more variable than both nonpatient groups. Siblings occupied an intermediate position, displaying higher thresholds than controls and lower thresholds than patients. Table 2 also shows that both patient groups required more than twice as much luminous energy as the control subjects for $50 \%$ chancecorrected detection.

Inspection of the distributions of visual thresholds indicated that 17 of the 32 patients $(53 \%)$ had higher thresholds than any of the 18 control subjects.

A Bartlett-Box $\mathrm{F}$ test for homogeneity of variance yielded a significant $F$ value $[F(3,61)=9.40, p<.01]$. Scheffé (1959) has suggested that when sample sizes are about equal, parametric analyses are appropriate despite inequalities in group dispersions. Therefore, parametric
Table 2

Mean Visual Thresholds (in Millilamberts/Milliseconds) and Standard Deviations of Subjects in Experiment 2

\begin{tabular}{llcc}
\hline \multicolumn{1}{c}{ Group } & N & Mean & SD \\
\hline Schizophrenics & 17 & .52 & .33 \\
Depressives & 15 & .47 & .34 \\
Siblings & 15 & .34 & .21 \\
Controls & 18 & .23 & .08 \\
All Patients & 32 & .49 & .33 \\
All Nonpatients & 33 & .28 & .16 \\
\hline
\end{tabular}

analyses were employed in the present experiment.

A one-factor analysis of variance was carried out to determine whether the subject groups differed significantly with respect to visual threshold. This analysis yielded a significant $F$ value $[F(3,61)=4.31, p<.01]$. The Newman-Keuls multiple-range test was carried out to determine the nature of the group differences. Results of this analysis indicated that, at the 5\% level of significance, (1) schizophrenic and depressive patients displayed higher thresholds than nonsibling controls, and (2) siblings did not differ from either schizophrenic patients or controls. ${ }^{2}$

A one-factor analysis of variance was conducted to assess whether the subjects differed with respect to within-subjects variability. The SIQR of the signal levels revisited in the "up" and "down" staircases was employed as an index of variability. The $F$ value resulting from this analysis was not significant, indicating that patients did not differ from nonpatients in the variability of their staircase performances.

\section{GENERAL DISCUSSION}

In two independent experiments, psychiatric patients displayed significantly less visual sensitivity than did nonpatient control subjects. Patients in both studies required about twice as much luminous energy (a difference of $.3 \mathrm{log}$ unit) for absolute threshold detection. This finding is consistent with those of earlier studies (Gerard, 1964; Granger, 1957; Rubin \& Stein, 1960). The difference in visual thresholds between patients and nonpatients in these studies ranged from .1 to $.5 \log$ units. Since about $50 \%$ of the patients of the present research exhibited higher thresholds than any control subject, the patient-nonpatient group differences in visual sensitivity are probably not due to extreme anomalies found in a few patients, but rather, they characterize a substantial proportion of the patient group. The use of a criterion-free forced-choice procedure and the finding that intraindividual variability did not differ across subject groups lend further credence to the conclusion that there are genuine patient-nonpatient differences in visual sensitivity. For all subjects, ascending and descending staircases converged, thereafter remaining around the signal level reached at the point of convergence. This indicated that all subjects were performing the task properly.

Although response-bias factors have been eliminated, the question still remains as to what might underlie the observed patient-nonpatient sensitivity differences. Rubin and Stein (1960) have noted the importance of adrenergic and cholinergic mechanisms as a possible interpretation of their data. They cite studies showing that LSD-25 (a drug known to produce an apparent "model psychosis" in normals) and certain cholinergic agents elevate absolute visual threshold. Beck (cited in Gerard, 1964) provided evidence that the schizophrenic's decreased 
sensitivity may be related to a mild hypoxia. Also, the retina contains high concentrations of dopamine, a neurotransmitter substance that has been implicated in schizophrenia (Snyder, 1978). Finally, pupil size may be a factor. There is some evidence that schizophrenic patients have significantly smaller pupil diameters than do normal controls (Hakerem \& Lidsky, 1975; Hakerem, Sutton, \& Zubin, 1964). Future investigations of visual sensitivity should control for pupil size as a possible confounding factor.

One might question whether the raised visual thresholds of patients could be attributed to a drug effect, since all patients of the present research were receiving medication. However, in neither experiment did the correlations between visual threshold and mean daily equivalent dosage of chlorpromazine (Davis, 1976) reach statistical significance. Further, most of the earlier visual experiments reporting similar patient-nonpatient differences were conducted prior to the introduction of the neuroleptics in the 1950s.

Earlier studies have underscored the potential importance of more clearly delineating the types of psychiatric patients in investigations of visual sensitivity (Gerard, 1964; Granger, 1954, 1956). These studies indicate there may be differences among the visual sensitivities of different psychiatric groups. Therefore, diagnostic criteria must be specified if psychiatric research is to advance beyond statements of patient-nonpatient differences. Even when diagnostic criteria are employed, the experimental psychopathologist often faces the difficult task of interpreting trends among diverse clinical samples. It is well known that schizophrenia, itself, is made up of a heterogeneous group of disorders, and there is increasing evidence that "depressive" patients should not be classified under the same rubric (Andreasen \& Winokur, 1979; Winokur, 1979).

Future investigations should also obtain information on the symptomatology of each patient tested. Perhaps visual sensitivity correlates with certain symptoms of psychopathology, irrespective of the diagnosis in which these symptoms are manifested. Brain-behavior relationships may be clarified at the symptom, rather than the diagnostic, level of analysis. ${ }^{3}$

\section{REFERENCES}

Andreasen, N. C., \& Winokur, G. Secondary depression: Familial, clinical, and research perspectives. American Journal of Psychiatry, 1979, 136, 62-66.

Babkoff, H., Sutton, S., \& Zubin, J. A comparison of psychiatric patients and normal controls on the integration of auditory stimuli. The Brain and Behavioral Sciences, in press.

Bruder, G., Spring, B., Yozawitz, A., \& Sutton, S. Auditory sensitivity in psychiatric patients and non-patients: Monotic click detection. Psychological Medicine, in press.

Bruder, G. E., Sutton, S., Babkoff, H., Gurland, B. J., Yozawitz, A., \& Fleiss, J. L. Auditory signal detectability and facilitation of simple reaction time in psychiatric patients and non-patients. Psychological Medicine, 1975, 5, 260-272.

Campbell, R. A. Detection of a noise signal of varying duration. Journal of the Acoustical Society of America, 1963, 35, 17321737.

Clark, W. C. The psyche in psychophysics: A sensory-decision theory analysis of the effect of instructions on flicker sensitivity and response bias. Psychological Bulletin, 1966, 65, 358-366.

Clark, W. C., Brown, J. C., \& Rutschmann, J. Flicker sensitivity and response bias in psychiatric patients and normal subjects. Journal of Abnormal Psychology, 1967, 72, 35-42.

Cornsweet, T. N. The staircase-method in psychophysics. American Journal of Psychology, 1962, 75, 485-491.

Davis, J. M. Comparative doses and costs of antipsychotic medication. Archives of General Psychiatry, 1976, 33, 858-861.

EDWARDS, A. E. Experimental design in psychological research (4th ed.). New York: Holt, Rinehart, \& Winston, 1972.

Emmerich, D. S., \& Levine, F. M. Differences in auditory sensitivity of chronic schizophrenic patients and normal controls determined by use of a forced-choice procedure. Diseases of the Nervous System, 1970, 31, 552-557.

FriTh, C. D. Abnormalities of perception. In H. J. Eysenck (Ed.), Handbook of abnormal psychology (2nd ed.). San Diego, Calif: Knapp, 1973.

Gerard, R. W. The nosology of schizophrenia: A co-operative study. Behavioral Science, 1964, 9, 311-333.

Granger, G. W. The night visual ability of psychiatric patients. British Journal of Physiological Optics, 1954, 11, 226-232.

Granger, G. W. Dark adaptation in anxiety states and hysterics. British Journal of Physiological Optics, 1956, 13, 234.

Granger, G. W. Night vision and psychiatric disorders: A review of experimental studies. Journal of Mental Science, 1957, $103,48-79$.

Green, D. M., \& Swets, J. A. Signal detection theory and psychophysics. New York: Wiley, 1966.

HAKeRem, G., \& Lidsky, A. Characteristics of pupillary reactivity in psychiatric patients and normal controls. In M. L. Kietzman, S. Sutton, \& J. Zubin (Eds.), Experimental approaches to psychopathology. New York: Academic Press, 1975.

Hakerem, G., Sutton, S., \& Zubin, J. Pupillary reactions to light in schizophrenic patients and normals. Annals of the New York Academy of Sciences, 1964, 105, 820-831.

Jenness, D., Kietzman, M. L., \& Zubin, J. Science of human behavior: Contributions of the psychological sciences. Cognition and perception. In A. M. Freedman, H. I. Kaplan, \& B. J. Sadock (Eds.), Comprehensive textbook of psychiatry-II (2nd. ed., Vol. 1). Baltimore: Williams \& Wilkins, 1975.

Malone, J. R. L., \& Hemsley, D. R. Lowered responsiveness and auditory signal detectability during depression. Psychological Medicine, 1977, 7, 717-722.

Rubin, L. S., \& Stein, G. H. Scotopic visibility in normals and psychotics. Journal of Clinical and Experimental Psychopathology and Quarterly Review of Neurology and Psychiatry, 1960, 27, 231-239.

SChefFÉ, H. The analysis of variance. New York: Wiley, 1959.

SNyder, S. H. Dopamine and schizophrenia. In L. C. Wynne, R. L. Cromwell, \& S. Matthysse (Eds.), The nature of schizophrenia-New approaches to research and treatment. New York: Wiley, 1978.

Spitzer, R. L., EndicotT, J., \& Robins, E. Research diagnostic criteria: Rationale and reliability. Archives of General Psychiatry, $1978,35,773-782$.

Sutton, S. Fact and artifact in the psychology of schizophrenia. In M. Hammer, K. Salzinger, \& S. Sutton (Eds.), Psychopathology: Contributions from the social, behavioral, and biological sciences. New York: Wiley, 1973.

WinokUR, G. Unipolar depression-Is it divisible into autonomous subtypes? Archives of General Psychiatry, 1979, 36, 47-52.

Zubin, J., Salzinger, K., Fleiss, J. L., Gurland, B., Spitzer, R. L., EndicotT, J., \& Sutton, S. Biometric approach to psychopathology: Abnormal and clinical psychology-Statistical epidemiological, and diagnostic approaches. Annual Review of Psychology, 1975, 26, 621-671.

\section{NOTES}

1. See Bruder et al. (1975) for a description of the specific details of the BUDTIF procedure.

2. Subsequent to the present analysis, subjects were reclassified on the basis of agreement between the diagnoses of two experienced raters. Although the composition of diagnostic groups changed radically, analysis of the visual thresholds based on the subsequent classification of subjects did not alter the findings reported in the present paper.

3. Scores on 20 factors of psychopathology were obtained for patients of the present research. Visual threshold was significantly $(p<.05)$ correlated with scores on one factor, auditory hallucinations, separately for Experiment 1 and for Experiments 1 and 2 combined.

(Received for publication October 30, 1979.) 